\title{
EL LABORATORIO DE LOS DIBUJANTES: SOCIABILIDAD Y POLÍTICA ENTRE LOS CARICATURISTAS ARGENTINOS (1930-1960)
}


EL LABORATORIO DE LOS DIBUJANTES: SOCIABILIDAD Y POLÍTICA ENTRE LOS CARICATURISTAS ARGENTINOS(1930-1960)

Resúmen:

Intentaremos reconstruir el colectivo de artistas humorísticos argentinos, sus relaciones, así como sus desempeños en publicaciones de diversa índole. Tomamos como inicio el lanzamiento de Tía Vicenta en Agosto de 1957 y como final el lanzamiento de Primera Plana, en Noviembre de 1962 (con referencias a su formación profesional en 1930 y 1940). Nuestra pregunta es: ¿estos vínculos tomaban la forma de una red, una sociabilidad o un círculo artístico?

Palabras Clave: Caricatura política; Tía Vicenta; Landrú; Lino Palacio; Argentina

\section{O LABORATÓRIO DOS DESENHISTAS: SOCIABILIDADE E POLÍTICA ENTRE OS CARICATURISTAS ARGENTINOS (1930-1960)}

Resumo:

O objetivo consistirá em reconstruir o coletivo de artistas humorísticos e as suas relações, assim como as suas filiações e desenvolvimentos em publicações de diversas índoles. Tomaremos como ponto inicial o lançamento de Tía Vicenta em Agosto de 1957 e como ponto final o lançamento de Primera Plana, em Novembro de 1962 (mais seu passado de formação profissional em 1930 e 1940).Nossa pergunta é: estes vínculos tinham a forma de uma rede, uma sociabilidade ou um círculo artístico?

Palavras chave: Caricatura política; Tía Vicenta; Landrú; Lino Palacio; Argentina

\section{THE LABORATORY OF CARTOONISTS: SOCIABILITY AND POLITICS AMONGST ARGENTINE CARICATURISTS (1930-1960)}

\section{Abstract:}

The aim will be to reconstruct the collective of humoristic artists and their relationships, as well as their affiliations and developments in publications of different nature. We will take as a starting point the launch of Tía Vicenta in August 1957 and ending point the launch of Primera Plana, in November 1962 (plus its training past in 1930 and 1940). Our question is: these links had the form of a network, a sociability or an artistic circle?

Keywords: Political caricature; Tía Vicenta; Landrú; Lino Palacio; Argentine 


\section{UN CAMPO EN CAMBIO Y RE-ESTRUCTURACIÓN}

Luego de que la polvareda de la Revolución Libertadora se hubiese asentado el campo del humor gráfico argentino se encontró en un momento de cambio y de renovación.

Durante el peronismo las revistas de humor gráfico y político habían existido (GENÉ, 2010) pero todas o se habían dedicado al humor costumbrista y familiar (Rico Tipo, Patoruzú) o habían construido su sátira política con cuidado de no pintar de manera negativa al peronismo. El espacio que parecía haber quedado vacante desde el cierre de la famosa revista Cascabel ${ }^{1}$ era el de una revista teóricamente independiente que se burlase de todos y con todos los participantes del elenco político. Una revista sin partidos, sin preferencias, sin condicionamientos políticos. Ese lugar simbólico será el que vendrá a ocupar Tía Vicenta.

Este valor tenía larga data en la historia de la caricatura política en el país. Había existido desde los tiempos de El Mosquito (o sea, casi desde sus inicios). Éste semanario incorporaba el adjetivo de independiente en su subtítulo, pero "tal autonomía de los poderes políticos constituidos o en lucha de serlo es difícil de sostener al revisar las páginas del periódico - durante el período roquistajuarista, casi obsecuente-“. (ROMAN, 2011, p. 284) La etiqueta de la independencia, entonces, era históricamente más bien una forma de diferenciarse de cierta prensa abiertamente facciosa y también era una forma de garantizar un ambiente caricaturesco limpio, una imparcialidad difícilmente sostenida.

Muchos de los protagonistas de la época se embanderan con éste mismo valor, comenzando por Landrú, editor y alma mater de Tía Vicenta, arco conductor y renovador de esta promesa en este período:

La revista tenía éxito entre los mismos políticos, porque se trataba de una cosa nueva para la Argentina y estaba abierta a todas las corrientes. Me ficharon y tildaron de nacionalista, de demócrata cristiano, de comunista, de militarista, de antimilitarista; pero lo bueno era que la revista circulara y fuese leída por gente de diferentes sectores y hasta de ideologías opuestas. (RUSSO, 1993, p. 24).

Esta declaración encierra otro de los patrones sobre el cual se organizaba la propuesta de Tía Vicenta: la novedad. Desde su subtitulo, la revista pregonaba que era "del nuevo humor". Esta aclaración tiene sentido cuando uno revisa el campo del humor gráfico argentino en 1955. Como hemos dicho, Rico Tipo y Patoruzú (junto con Patoruzito, la versión menuda de Patoruzú) eran la 1Publicada entre 1941 y 1946, fue crítica de Perón, a quién comparó con una pera. Cerrada por el peronismo no directamente sino acudiendo a tácticas intimidatorias que incluyeron "El retiro de publicidad y algunos allanamientos en la redacción, que la revista se esfuerza en comentar con cierta gracia” (GENÉ, 2009, p. 104). 
dupla más duradera, las empresas más establecidas, del humor gráfico argentino ${ }^{2}$. Sin embargo, estas revistas estaban dominadas por un humor que tenía mucho que ver con la personalidad de sus creadores, ambos dibujantes.

Rico Tipo (fundada en 1944) era dirigida por Guillermo Divito, y había sido fundada luego de su marcha de Patoruzú, disconforme con las políticas editoriales ejercidas por Dante Quinterno, creador del famoso indio 3 . En su momento también pregonó un nuevo humor, más arriesgado, pero pronto se convirtió en la platea de la clase media porteña, en una revista que, a mitades de los 50, se caracterizaba por las chicas de Divito y por la serie "Buenos Aires en Camiseta" (dibujada por Calé), colección de modismos, escenas callejeras y lugares comunes de los habitantes de la ciudad. La revista albergaba, en el año 1955-56, a otros dibujantes muy destacados, como Alfredo Mazzone, Rafael Martínez, el mismo Landrú y Oski, otro proponente de línea temblorosa y humor absurdo tan caro al primero. En la revista de Divito el humor político solamente se filtrará a través de comentarios sobre el aumento del costo de vida o la manera en que las huelgas afectan la vida cotidiana.

Patoruzú (1936) reflejaba de manera más cabal la ideología y visión del mundo de su autor. Como dice Steimberg:

La identidad social de Patoruzú es tan intocable y tan inaprensible como su dinero. (... ) La situación social y económica de Patoruzú se parecería al ideal de un estanciero real, que además fuera un hombre de derecha, y que quisiera no solo conservar intacto y libre de peligros su patrimonio, sino también intacta y no cuestionable su condición social. (STEIMBERG, 1977, p. 66).

A esta rigidez se unía la rigidez de la revista, compuesta por secciones fijas y no mutables que, además de las historietas, incluían notas sobre cine, editoriales con un fuerte tenor político y una pequeña sección para niños. $\mathrm{Pa}$ toruzito (1945) ampliaría ésta sección volviéndola revista, con largas aventuras humorísticas con continuará.

Cuando Tía Vicenta apareció en Agosto de 1957, tomó la posta de la novedad y la independencia pero también se benefició de una nueva relación entre el gobierno y la prensa. A diferencia del período peronista, en el cual se implementaron "lo que podríamos llamar 'medidas restrictivas', básicamente la censura de los contenidos y el control material de los insumos de los medios"

2Los números de venta son difíciles de precisar, el historiador y caricaturista Oscar Vázquez (Entrevista a Oscar Vázquez Lucio, 2007) indica, sin embargo, que a mediados de los años 40 tanto Rico Tipo como Patoruzú editaban unos 250 mil ejemplares semanales cada una. Mientras tanto, Laura Vázquez (2010, p. 25) indica que por la misma época Patoruzito llegaba a los 300 mil. Las cifras probablemente eran bastante inferiores a mitades de los 50.

3 Tía Vicenta nacería cuando Landrú se fuese de Rico Tipo alegando que Divito le había negado la posibilidad de un suplemento de humor político: "No, la política no me gusta. No la entiendo y mientras yo dirija Rico Tipo no la vamos a abordar” (RUSSO, 1993, p. 22) 
(Varela, 2007, p. 6) durante el nuevo régimen la polarización se invertiría y, si bien el nombre y los medios de Perón y el Movimiento Peronista serían interdictos, los valores de independencia y novedad serían promovidos.

Landrú, en diferentes reportajes, indica que "el primer número casi íntegramente lo hice yo, con una colaboración de Del Peral"4 (VÁZQUEZ, 1987, t.2, p. 249). Sin embargo, en la segunda y tercera página del mismo vemos una nota del staff donde se nombran como colaboradores a Faruk, Quino y Garaycochea. Faruk es Jorge Palacio, hijo de Lino Palacio, famoso humorista y caricaturista político cuya trayectoria reconstruiremos en el siguiente apartado de este trabajo. Quino es Joaquín Lavado, quién alcanzaría la fama como creador de Mafalda, tira que aparecería por primera vez en la revista Primera Plana en 1964. En esa misma revista Lino Palacio, bajo el nombre de Flax, realizaría caricaturas políticas sobre la situación nacional. Garaycochea es Carlos Garaycochea, quién se iniciaría como caricaturista político en Qué, la revista dirigida por Rogelio Frigerio que impulsaría la candidatura de Frondizi desde principios de 1956. Allí también colaboraba Quino con pequeñas viñetas de humor blanco y apolítico.

A lo largo de sus primeros tres años, Tía Vicenta mantendrá un formato estable, de un tamaño ( 32 centímetros x 25 centímetros $^{5}$ ) similar a un magazine pero que también recuerda a los viejos periódicos ilustrados. La tapa será a un solo color (el interior en blanco y negro, con excepción de ciertas páginas centrales a dos colores), la gran mayoría de ellas ilustradas por Landrú, una gran imagen sobre la que se imprime un solo color y encima de la cual va el título. A su costado, una barra con una descripción de los contenidos más destacados. La revista contendrá en su interior una gran cantidad de humor escrito (aproximadamente la mitad y muchas veces más de su contenido total) y dentro del humor gráfico, una división entre humor atemporal y no político y el humor político.

Dentro de ésta última categoría, los colaboradores que más se repetirán durante los inicios serán Faruk (con más de 70 colaboraciones en los primeros dos años) $)^{6}$, Siulnas (21), Nowens (23), Alfredo Olivera (20) y Basurto (14). Esto sin contar con Landrú, quién participará de todos los números en múltiples roles: como editor, como escritor, como caricaturista y también como fotomontajista, un formato de imagen que aparece repetidas veces en Tía Vicenta, una

4Carlos Del Peral, el secretario de redacción de la revista, serviría en esta capacidad durante los primeros años, retirándose alrededor del número 100 por una confusa disputa con Landrú acerca del encarcelamiento de un fotógrafo colaborador.

5 Paradójicamente, el mismo tamaño de Descamisada, la revista de humor peronista publicada entre 1946 y 1949.

$6 \mathrm{El}$ caso de Faruk es particularmente curioso, ya que representa un link entre las empresas editoriales de Landrú y las de Lino Palacio. Así como participaba con viñetas políticas de casi cada número de Tía Vicenta, también dirigía, con su nombre real (Jorge Palacio) la revista Avivato, fundada en 1953 con el nombre de uno de los personajes más famosos de su padre. Allí éste realizaba viñetas de política extranjera. A partir de 1955, la política nacional también ocuparía las páginas de Avivato. Sin embargo, Lino Palacio nunca participó de Tía Vicenta. 
vez más recordando a las imágenes de los periódicos ilustrados del siglo XIX, pero esta vez con un giro totalmente moderno, reformateado, canibalizado de tal modo que esos elementos se vuelven collage y absurdo.

Tía Vicenta será, por lo tanto, un órgano de asociación, un nodo que agrupará a diversos dibujantes. Sin embargo, estos dibujantes no se desempeñaban exclusivamente allí, prestando sus talentos para una variedad de revistas. En primer lugar, exclusivamente humorísticas. A las antes mencionadas Patoruzú y Rico Tipo se agregará también en 1957 el suplemento mensual de la última, Dr. Merengue, donde también dibujaran Garaycochea, Siulnas, Quino, Calé y por supuesto Divito. El objetivo era "tener una segunda publicación más moderna que 'Rico Tipo', donde notas y chistes tengan un nivel más 'intelectualizado"' (VÁZQUEZ, 1987 t.2, p. 241). Otra vez más el clamor de modernización y sofisticación. Otra publicación es Popurri, lanzada por Luis J. Medrano, dibujante estrella de La Nación, en 1955, en donde también dibujarán Garaycochea, Quino y el mismo Landrú unos cuantos meses antes de lanzar Tía Vicenta.

Estos dibujantes a su vez colaboraban en una amplia gama de revistas de interés general, como Vea y Lea, donde Landrú tenía una página de humor costumbrista que fue mutando a político entre 1955 y 1957.

Sin embargo, para continuar con nuestra exploración de este campo cambiante y sus conexiones, creemos pertinente ejemplificar la manera en que los caricaturistas se movían y se conectaban con la reconstrucción de dos trayectorias similares pero dislocadas, de influencia reciproca y también de cierta tipicidad en el medio: las de Lino Palacio y Landrú.

\section{DOS TRAYECTORIAS ESPECULARES}

Lino Palacio nació en 1903 en San Telmo, Buenos Aires. Su padre era arquitecto y, como todo biografía retrospectiva, abundan las historias sobre su precariedad y avidez al dibujo, que lo llevo incluso a "dibujar en las paredes de su casa paterna con carbonilla hasta los 8 años" según su biografía en el Museo del Dibujo.

Precoz autor, su padre, mediante contactos amistosos con el editor de La Razón, logra que le publiquen su primer dibujo cuando tenía 16 años (1919). Estudia y se recibe de arquitecto, pero no construye mucho. Enseña dibujo y artes plásticas en el Nacional Buenos Aires. En 1925, "salió una resolución por la cual no se podía enseñar sin título. Yo tenía que dejar todas mis cátedras y me resistía. Un día se me ocurrió dar libre todas las materias de Bellas Artes. Me preparé y en una semana rendí libre las 21 materias y obtuve mi título" (BORRONI, 1975). Entre 1925 y 1930 publica la revista El Cuco junto con el músico Adolfo Rosquellas. De publicación irregular y de acuerdo a los fondos con los que disponían, la revista podría pasar por un antiguo fanzine.

En 1930 crea su primer personaje fijo y duradero: Ramona. Ésta es publicada en el diario La Opinión, "un diario armado por el gobierno de Uriburu con 
objetivos de prensa y propaganda oficialista. No duró mucho, pero sirvió al menos para que la primera Ramona empezara, todos los días, a enrarecer desde sus páginas las buenas conciencias patronales" (PAULS, 1995, p. 51). Ramona era una empleada gallega con la particularidad de entender absolutamente todo de forma literal.

En 1931 comienza a dibujar el suplemento infantil del diario La Prensa, trabajo que es el preludio de la primera labor que lo haría famoso: en 1936 dibuja su primera tapa de Billiken, mítica revista infantil de Constancio García Vigil. Allí se mantiene durante más de 30 años:

Un día nos encontramos con Carlitos Vigil en un club de bridge y me preguntó si me animaba a hacer las tapas de Billiken. Le dije que sí y le mandé unas cuantas, le gustaron, y ahí empezó la serie. (...) Recibía centenares de cartas, de maestros y alumnos de todo el país. Me pedían originales para colgar en el aula. Por eso hoy no tengo ningún original: todos los fui regalando a las escuelas. (Las Tapas de Lino Palacio en Billiken, 29/11/2000).

En algún momento de la segunda mitad de los 30 se hace cargo de la caricatura política de El Diario, tratando la actualidad nacional. Este trabajo se mantiene hasta 1941, cuando el periódico cierra y consiste en su primera incursión en el terreno de la caricatura política.

Mientras tanto, en Abril de 1938 aparece por primera vez, en el diario La Prensa, Don Fulgencio, el hombre que no tuvo infancia, "La hice porque me lo pidieron de La Prensa. Ellos nunca habían publicado una historieta y querían una que fuera muy especial." (Borroni, 1975). Este demostraría ser uno de sus personajes más perdurables, dando lugar a toda una familia de personajes secundarios, entre los cuales se contaran una multiplicidad de la estirpe más extravagante: los monovocálicos, sujetos que solo hablan con un sonido. Don Fulgencio protagonizaría una controversia en 1940:

Por esa época yo tenía una agencia de publicidad, y un cliente, dueño de una cadena de tiendas, me sugirió que para un nuevo café que importaría de Europa le pusiéramos el nombre de Don Fulgencio. (...) El día que Ezequiel Paz [director de La Prensa] llegó de Francia, leyó la propaganda del café en un recuadro bastante grande que rezaba: "Don Fulgencio llegó de Europa". Imagínese, se enfureció y ordenó que sacaran la tira del diario. (La última travesura de Don Fulgencio, 1979).

Por ello pasaría a La Razón donde se publicaría hasta septiembre de 1979. En ese mismo diario, en 1939, iniciaría su labor (bajo el seudónimo Flax, que conservaría toda su carrera) como "dibujante de la guerra". Esta tarea se extendería hasta 1945 y pasaría a la historia por su combinación de comentario 
político detallado (el ritmo diario imponía una atención al detalle que hace que muchos nombres presentes en las tiras hoy nos suenen ajenos) con rimas un tanto forzadas y un estilo de dibujo en suma caricaturesco, donde los grandes protagonistas son definidos por un puñado de líneas nerviosas que se curvan, por un rasgo fisionómico principal y por un ítem de vestimenta: el pecho curvo y henchido de Mussolini (y su vestimenta marcial), los bigotes y el sombrero de Stalin, el bigote y la chaqueta prendida de Hitler.

Paralelo a este desempeño que le traería fama en un nuevo sector del público, Palacio colaboraría en la revista Cascabel, desde su fundación, con un dibujo sobre la guerra, diferente de aquellos publicados en La Razón.

El 17 de Octubre de 1945 saldría a la calle su único emprendimiento editorial propio, a la manera de sus contemporáneos Divito y Dante Quinterno: se Ilamó Don Fulgencio, como su personaje más famoso, y se subtitulaba "la revista para todos los de la casa". Solo se publicaron 36 números antes de cerrar en Junio de 1946. A pesar de que no hemos podido dilucidar los motivos reales de su cierre, esta revista sirvió como espacio de prueba para muchos jóvenes dibujantes. El mismo Landrú diría "Lino Palacio era el número uno. Yo lo respetaba mucho como dibujante clásico, aunque mis preferencias se inclinaban por Oski o Cota, que representaban un estilo de humor decididamente moderno" (RUSSO, 1993, p. 15). En esta cita se cruzan la admiración por un maestro y al mismo tiempo una visión generacional del humor. Luego del cierre de Don Fulgencio, Lino Palacio jamás volvió a dirigir una revista.

Luego del fin de la Segunda Guerra Mundial y de su aventura editorial, Palacio crea un nuevo personaje, Avivato (aparece por primera vez el 23 de septiembre de 1946 en La Nación) y a partir de 1950 dibuja en Caras y Caretas una viñeta de política mundial. Justifica su alejamiento de la política nacional diciendo que todo humorista político debe estar "un poco, en la vereda de enfrente del oficialismo" (Vázquez, 1987 t.2, 151-153). Narra una anécdota en la cual Perón lo habría llamado a su despacho para preguntarle porque no realizaba humor político y pedirle que le remita dibujos al Secretario de Prensa para ser publicados. A lo que contesta "eso sería en periódicos o revistas con tendencia y a mí no me interesaba” (Vázquez, 1987 t.2, 151-153). Una vez más observamos el reclamo de independencia de las tendencias políticas y las facciones, la necesidad de despegarse de una aclamación explícita de un régimen.

En 1953 su hijo Jorge Palacio inició, junto con el periodista Luis Alberto Reilly, la revista Avivato con su aprobación. Aquí volvió a dibujar sobre política internacional.

En 1962 ingresa desde el primer número al semanario Primera Plana, donde realizará fuertes críticas a Illia y se disputará con Landrú la creación de la imagen de la tortuga con la cual quedará asociado este presidente.

Landrú, por su parte, nace en Buenos Aires en 1923, con el nombre de Juan Carlos Colombres, dos décadas luego de Lino Palacio, por lo cual su trayectoria hasta el punto final de nuestro trabajo es más corta. Así como éste, las 
anécdotas tempranas de Landrú incluyen la realización completa de su futuro artístico, comenzando por el dibujo de una nueva Biblia en sus años de secundaria. Estudia arquitectura a principios de los 40, pero abandona a los dos años. De 1943 a 1948 trabaja como administrativo en Aeronáutica. Luego ingresa a trabajar en Tribunales, donde trabaja hasta 1953, momento en que se dedica exclusivamente al dibujo.

Landrú comienza su labor profesional hacia mitades de los 40. Según sus propias palabras "Durante los años de mi formación había comenzado en Europa una corriente de humor absurdo con la cual me sentí plenamente identificado (... En Argentina Oski y yo comenzamos a practicar y difundir esa línea" (RUSSO, 1993, p. 13). Sus primeros dibujos son publicados en la revista Popurri (1946) y en Don Fulgencio (donde realizaba falsas crónicas históricas delirantes). Colabora en Cascabel hasta su cierre y luego salta a la revista Vea y Lea, en la cual "me pagaban por cierta exclusividad. No podía colaborar con revistas serias (...) pero tenía libertad para hacerlo en revistas de humor" (RUSSO, 1993, p. 18). En 1951 intentaría, junto con Palacio, quién es a la vez una especie de mentor y competidor, lanzar una nueva revista de humor, al estilo de la española La Codorniz, cuyo director había visitado hacía poco el país. Sin embargo "las cuotas de papel en esa época las otorgaba o negaba el Ministerio de Comercio", Landrú realiza una tapa donde alude a la CGT y entonces "el chiste resultó inaceptable y nos niegan la cuota de papel” (RUSSO, 1993, p. 20). Su siguiente hito será la creación de Tía Vicenta.

Ambos dibujantes tienen bastantes cosas en común, a pesar también de sus diferencias: ambos reivindican un tipo de humor político que se pretende independiente, o al menos a-partidario. Ambos, en su desfasaje generacional, se consideran a la moda y cultivan una imagen de dandy: Lino Palacio trabaja desde 1936 en una agencia de publicidad y funda en 1939 una propia, donde realiza innumerables bocetos de avisos de tabacos, trajes y bebidas. Asimismo, las anécdotas lo pintan como un personaje jovial y a tono con la época, inclusive a avanzada edad: "fuimos invitados a tomar una copa en un night club de la zona. Lino, con sus joviales 80 años, fue el primero que se decidió a bailar. La agilidad de sus movimientos era increíble" (anécdota narrada por Basurto, Lino Palacio y su Gente, 1989).

Landrú, por su parte, en gran parte del humor escrito de la Tía Vicenta de los primeros años hace un despliegue de grandes conocimientos sobre música popular: "Mucha gente llegó también a pensar que yo era dueño o socio de Mau-Mau, porque el nombre aparecía siempre en boca de María Belén y Alejandra como el boliche de onda" (RUSSO, 1993, p. 63). Al mismo tiempo, los primeros cuatro años de Tía Vicenta abundan en publicidades dibujadas por Landrú, predominantemente de boliches, ropas y bebidas.

Ambos fundan una sola empresa editorial y luego de su final sus siguientes emprendimientos están enmascarados bajo colaboradores cercanos (Lino Palacio y Avivato) o son de corta vida y desplazan a su creador de nuevo a un 
trabajo de encargo (Landrú y Tío Landrú, la continuación de Tía Vicenta).

Ambos intentan enmascarar, bajo la fachada de un supuesto apoliticismo, un velado antiperonismo, momento político nacional crucial que marca sus carreras de caricaturistas políticos y que, con el trauma del cierre de Cascabel, encierra su apreciación del humor del período como obsecuente: "El único humor político que se aceptaba era el oficialista. Más aún, se promovían todas las variantes que ridiculizaran a los enemigos del régimen" (RUSSO, 1993, p. 20); o "entonces publicaría en revistas con tendencia".

Ambos funcionan como mentores y promotores de nuevas generaciones, que publican en sus revistas. Ambos reivindican una forma de actividad que oscila entre lo creativo y lo industrial, entre la humildad y el orgullo. Palacio, por ejemplo, hablando de cómo sus personajes habían sido sugeridos por sus editores, pero clamando que "los únicos personajes que se llevaron al cine, en todo el mundo, fueron Don Fulgencio, Avivato y, recientemente, Superman" (La última travesura de Don Fulgencio, 1979). O Landrú diciendo que "El día que la cerró Onganía el distribuidor había pedido 450000 ejemplares de Tía Vicenta"7 (DA COSTA, 1999).

Quizás la gran diferencia está dada en su manejo del alter ego, en su manera de entrar y salir de los mundos complementarios de la sátira política y el humor más inofensivo e infantil. Mientras que Palacio realiza una operación de desdoblamiento en la cual quiere ocultar / dividir a sus diferentes públicos, temiendo una contaminación de su alter ego político, "un caricaturista algo agresivo, pero más bien constructivo" (BORRONI, 1975) de su labor como ilustrador de la vida infantil, Landrú se transforma por completo. El J.C. Colombres con el que firmaba sus colaboraciones primordiales muta en Landrú, por temor a represalias políticas pero también por una labor alquímica en la cual se convierte totalmente en otro. Lo que en Palacio es seudónimo en Landrú es nombre y eso quizás explica su predilección por una forma de humor más puramente político (aunque cruzado por una gran dosis de nonsense).

\section{3 ¿SOCIABILIDAD,CÍRCULO,RED?}

El apartado final de este trabajo se concernirá con dilucidar el enigma principal del mismo: ¿la manera en que los caricaturistas se relacionaban tenía la forma de una sociabilidad tradicional, de un círculo o de una red?

Esta pregunta involucra una disputa entre la historia y la sociología. El concepto de sociabilidad es uno que ha tenido una gran prédica entre los historiadores franceses, quienes ven en él una de las formulas más apropiadas para investigar los cambios en las formas de asociación pre-clasistas de los países europeos durante los siglos XVIII y XIX. Sin embargo existe muchas veces "la

7 Un número a todas luces exagerado: los datos del IVC muestran unos promedios de venta para el diario El Mundo (último hogar de la revista) del orden de 200000 ejemplares por mes. 
arraigada idea de que la sociabilidad es una categoría de sentido común que no necesita ser explicitada ni contextualizada, simplemente evocada" (BERNALDO DE QUIROS, 2008). Por ello, según Maurice Agulhon y otros proponentes de su uso hay que "hay que adoptar otros principios de clasificación de las asociaciones más acordes con las épocas consideradas, es decir, más históricos, sin que dejen de ser, por supuesto, sociológicos por naturaleza." (AGULHON, 2009, p. 43) El trabajo de este último escritor se concentra en el círculo burgués, una forma asociativa nacida bajo el modelo del club inglés, con su estatuto, su sede, sus reglas y sus miembros permanentes. Roger Chartier, mientras tanto, ha estudiado las formas del salón literario y los cafés en los tiempos previos a la Revolución Francesa, una forma de socialización aristocratizante, "el medio principal para que se organice el encuentro entre hombres de mundo y literatos, reunidos por los mismos pasatiempos, el juego, el debate, la lectura, la mesa" (CHARTIER, 1995, p. 174). Agulhon, también ha realizado excursiones en la sociabilidad obrera de principios del siglo XIX, basada en la sociabilización en el taller, la taberna, las asociaciones de ayuda mutua y otros lugares informales de reunión, muy diferente de "la fórmula del Círculo, algo más compleja de poner en práctica, puesto que hay que organizar su reglamento, su financiación y su gestión". (AGULHON, 1992, p. 156)

Como vemos este concepto está firmemente entroncado en un tiempo, un espacio y una clase social. Por contrapartida, el concepto de red, que ha tomado gran predicamento en las últimas décadas en la sociología, propone "un interés creciente por las propiedades relacionales (y las ontologías relacionales), en contraposición a las propiedades sustancialmente asignadas a seres que quedarían definidos por ellas" (BOLTANSKI, 2002, p. 214) que de ese modo "pretendían también emancipar a la sociología de las 'viejas' nociones de 'categorías', 'grupos', 'clases”' (BOLTANSKI, 2002, p. 223).

Asimismo, el concepto de red fue recuperado por un sector de la sociología francesa afín a la sociología de la ciencia, como una manera de unificar los campos enfrentados de la naturaleza, la ciencia y lo social de tal modo que "lo social no designa algo entre otras cosas (... ) sino un tipo de relación entre cosas que no son sociales en sí mismas" (LATOUR, 2008, p. 19). La idea de esta rama es "hacer lo más plano posible el mundo social para asegurar que el establecimiento de cualquier vínculo nuevo sea claramente visible" (LATOUR, 2008, p. 34). Esto quiere decir ampliar los actores posibles para incluir a no humanos y rastrear los vínculos en asociaciones eternamente cambiantes, abiertas y contingentes.

Es claro que estos dos puntos de vista se oponen. Entonces, ¿a qué clase de esquema respondía la forma asociativa de los caricaturistas argentinos en los 50 y 60? Hemos visto que compartían, de manera primordial, los espacios de publicación. Tía Vicenta fue una revista qué funcionó como un nodo donde cada uno enviaba sus dibujos y donde se comunicaban ("siempre consultábamos antes para no coincidir" $)$. Pero este formato también se insertaba en una

8Entrevista a Carlos Garaycochea realizada por el autor, Mayo de 2011. 
tradición previa dentro de la industria humorística local. No era un nodo exclusivo ni tampoco los creadores le debían lealtad absoluta. En parte esto, seguramente, respondía a una lógica exclusivamente económica: ningún productor independiente vive exclusivamente de un solo trabajo, pero también creaba lazos más fluidos y cambiantes, sin una redacción específica a la cual referirse como espacio de sociabilización.

La tarea misma del caricaturista, su aislamiento hogareño para la producción, también enfatizaba estos vínculos fluidos. Sin embargo, su condición de productores creativos les concebía una cierta conciencia de grupo. Como diría Quino mucho más tarde: "Pero diría que en general me llevo bien con todos, menos con Nik (...) Nik vino a crear un malestar por primera vez entre los dibujantes argentinos" (Maristain, 2004). Su labor conjunta y el hecho de dedicarse todos a la esotérica tarea del humor en dibujos les generaba una cierta idea de grupo de pertenencia. Hemos observado que existían vínculos entre los creadores de amistad, de respeto y de reciprocidad a la hora de darse trabajo.

Los espacios de sociabilidad mencionados por los dibujantes en general tienden a ser espacios públicos, de esparcimiento, donde se establece un tipo de vínculo no mediatizado por la producción: "un club de bridge", "un nightclub", "el Mau-Mau". Si bien a principios de los años 40: "Existía la Asociación de Dibujantes Argentinos, una especie de club gremial integrado por todos los humoristas e ilustradores (...) La asociación organizaba un salón anual con una sección dedicada al humor y otra a la publicidad, donde nos cruzábamos todos." (Russo, 1993, p. 15), no tenemos registro de si las actividades de la misma se mantuvieron con regularidad hasta los años 50 y 60.

Al mismo tiempo, esta fluctuación constante se unía a la misma definición de la tarea de los caricaturistas, en algún lugar entre el productor independiente y el empleado periodístico, entre el creador artístico y la simple mano contratada, de trasfondos generalmente de clase media y con formación universitaria pero dedicados a un trabajo que por momentos se asimilaba a lo más mecánico del trabajo obrero.

Por todas estas condiciones, por su inestabilidad y por la cualidad de lazos más bien débiles, basados en un oficio y en canales de expresión comunes, pero no en comunidades codificadas con lugares de reunión regulares (al decir de Boltanski (2002, p. 235): "El cuadro asalariado a tiempo pleno [... ] es sustituido por el colaborador intermitente cuya actividad puede ser remunerada de diferentes maneras") creemos que los lazos sociales que se tejían entre ellos respondían a la forma de una red, antes que a la del círculo o la sociabilidad tradicional.

Estos vínculos en red, sin embargo, no anulaban su condición social ni su sustancia (eran, al fin y al cabo, dibujantes cómicos) pero les permitían ejercitarse en una multiplicidad de publicaciones, compartir espacios entre colegas de ideologías diversas y, básicamente, desarrollar su actividad profesional de una manera tal que la hiciese sustentable. 


\section{REFERENCIAS}

AGULHON, M. El círculo burgués. Buenos Aires, Argentina; Siglo XXI Editores; 2009; 208 p. . Clase obrera y sociabilidad antes de 1848. Historia Social; Valencia, España; n. 12; p. 141-166; 1992.

BOLTANSKI, L. \& CHIAPELLO, E. El nuevo espíritu del capitalismo. Madrid, España; Akal; 2002; 720 p.

GONZALEZ BERNALDO DE QUIRÓS, P. La “sociabilidad” y la historia política. En Nuevo Mundo Mundos Nuevos; Biblioteca de Autores del Centro; 2008. Recuperado de: http://nuevomundo.revues.org/24082. Accedido el 27 de Mayo de 2012.

BORRONI, O. Lino Palacio, el arte de trepar al monte Olimpo. Siete Días Ilustrados; Enero 1975. Recuperado de: http://www.magicasruinas.com.ar/revistero/tambien/revtambieno74. htm. Accedido el 27 de Mayo de 2012.

CHARTIER, R. Espacio público, crítica y desacralización: los orígenes culturales de la Revolución Francesa. Barcelona, España; Gedisa; 1995; 264 p.

DA COSTA, A. Entrevista a Juan Carlos Colombres (Landrú). Sala Virtual de Lectura, 1999. Recuperado de: http://200.69.147.117/salavirtual/Entrevistas/landru.htm. Accedido el 27 de Mayo de 2012.

ENTREVISTA A OSCAR LUCIO VÁZQUEZ (SIULNAS). Caras y Caretas 2207 Febrero de 2007; $\mathrm{s} / \mathrm{n}$.

GENÉ, M. Risas, sonrisas y carcajadas en tiempos de Perón. Pasando revista al humor polítiCo. En SORIA, C., CORTES ROCCA, P. \& DIELEKE, E. (Eds.), Políticas del sentimiento. El peronismo y la construcción de la Argentina moderna. Buenos Aires; Prometeo; p. 88-102; 2009. GENÉ, M. Descamisada, la revista imposible (1946-1949). En PANELLA, C. y KORN, G. (Eds.), Ideas y debates para la Nueva Argentina. Revistas culturales y políticas del peronismo (1946-1955). La Plata, Argentina; Facultad de Periodismo y Comunicación Social, Universidad Nacional de La Plata; 409 p.; 2010.

LA ÚLTIMA TRAVESURA DE DON FULGENCIO. (11 de octubre de 1979). Mercado, 11 de Octubre de 1979. Recuperado de: http://www.magicasruinas.com.ar/revistero/argentina/don-fulgencio-lino-palacio.htm. Accedido el 28 de Mayo de 2012.

LAS TAPAS DE LINO PALACIO EN BILLIKEN. Revista Imaginaria, 29 de Noviembre de 2000. Recuperado de: http://www.imaginaria.com.ar/03/9/palacio.htm. Accedido el 28 de Mayo de 2012.

LATOUR, B. Nunca fuimos modernos. Ensayo de antropología simétrica. Buenos Aires, Argentina; Siglo XXI Ediciones; 2007; 224 p.

. Reensamblar lo social. Una introducción a la teoría del actor-red. Buenos Aires, Argentina; Manantial; 2008; 390 p.

LINO PALACIO Y SU GENTE. Catálogo de exposición homenaje a Lino Palacio en la Sociedad de Distribuidores de Diarios, Revistas y Afines, 1989. Recuperado de: http://transdisciplina4. tripod.com/133-lino_palacio-4.htm. Accedido el 28 de Mayo de 2012.

MARISTAIN, M. Quinografía. Página 12, Suplemento Radar; p. 4; 22 de febrero de 2004.

Recuperado de: http://www.pagina12.com.ar/diario/suplementos/radar/9-1247-2004-02-22. html. Accedido el 27 de Febrero de 2004.

PAULS, A. Lino Palacio. La infancia de la risa. Buenos Aires, Argentina; Espasa Calpe; 1995; $190 \mathrm{p}$.

ROMÁN, C. Argentinos y extranjeros en la batalla de la prensa satírica (1870-1893). 2011 (Doctorado en Historia) Cap. 4 de su tesis doctoral. 68 p. Facultad de Filosofía y Letras, UBA: Buenos Aires. 
RUSSO, E.; LANDRÚ. Landrú, Apuntes para una autobiografía. Buenos Aires, Argentina; El Ateneo Editorial; 1993; 163 p.

RUSSO, E. La historia de Tía Vicenta. Buenos Aires, Argentina; Compañía Editora Espasa Calpe; $1994 ; 177 \mathrm{p}$.

STEIMBERG, O. Leyendo historietas. Buenos Aires, Argentina; Ediciones Nueva Visión; 1977; $154 \mathrm{p}$.

VARELA, M. (2007). Peronismo y medios: control político, industria nacional y gusto popular. En Red de Historia de los Medios; Documentos; 2007. Recuperado de: http://www.rehime. com.ar/escritos/documentos/idexalfa/v/varela/Mirta\%20Varela\%20-\%20Peronismo\%20y\%20 medios.pdf. Accedido el 28 de Mayo de 2012.

VÁZQUEZ, L. (2010). El oficio de las viñetas, La industria de la historieta argentina. Buenos Aires, Argentina; Paidós; 2010; 351 p.

VÁZQUEZ, O. (1987), Historia del humor gráfico y escrito en Argentina t. 1 y 2. Buenos Aires, Argentina; Eudeba; 1987; t.1: 620 p., t.2: 620 p.

\section{Amadeo Gandolfo}

Doutorando em Ciências Sociais na Facultad de Ciencias Sociales da Universidad de Buenos Aires - UBA. Graduado em História pela Universidad Nacional de Tucumán (UNT). Bolsista do Consejo Nacional de Investigaciones Científicas y Técnicas - CONICET. Pertence ao grupo de pesquisa UBACyT "Das artes gráficas ao desenho: contribuições para una história social, técnica e cultural do desenho gráfico na Argentina" (FADU - UBA). 